
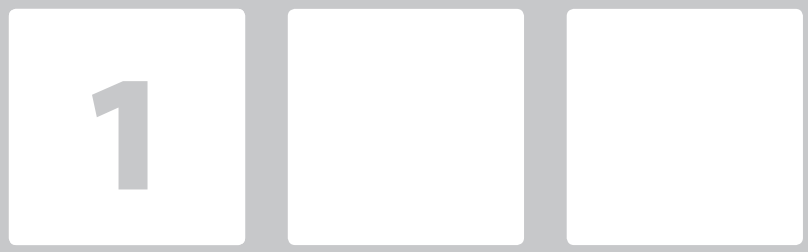

\title{
CAPITAL INTELECTUAL INDIVIDUAL E COLETIVO: ESTUDO EM UMA INDÚSTRIA QUÍMICA
}

\section{Individual and Collective Intellectual Capital: Study in a Chemical Industry}

\section{Bruna Pospichil}

Pesquisadora da Pós-Grad. em Gestão Empresarial da Univ. Feevale, Graduada em Gestão de Recursos Humanos pela Universidade Feevale. Porto Alegre, RS. Brasil.e-mail:autor1@xxx.com

\section{Raquel Engelman}

Doutora em Administração pela Univ. Federal do Rio Grande do Sul. Professor-pesquisador na Univ. Feevale. Porto Alegre, RS. Brasil. e-mail: autor2@xxx.com

\section{Serje Schimdt}

Doutorado em Adm. de Empresas pela UNISINOS. Professorpesquisador na Universidade Feevale. Porto Alegre, RS. Brasil. e-mail:autor2@xxx.com

\section{Cristine Hermann Nodari}

Pós-Doutorado em Inovação pelo Prog. Nac. de Pós-Doutorado da Coord. de Aperf. de Pessoal de Nível Superior (PNPD/CAPES). Profa da Univ. Feevale e no PPGA da Univ. Potiguar. Porto Alegre, RS. Brasil. e-mail:autor2@xxx.com

\section{RESUMO}

O Capital Intelectual consiste em todo e qualquer conhecimento útil que uma empresa possui. Essa pesquisa teve como objetivo analisar a relação entre o Capital Intelectual individual e o Capital Intelectual coletivo em uma indústria química. $O$ estudo pretende contribuir na percepção da relação entre - Capital Intelectual individual e coletivo e seus possíveis subsídios para as organizações do conhecimento. Para tanto, foi realizado um estudo de caso por meio da triangulação de dados coletados. Os principais resultados demonstram que a respeito do Capital Humano, os funcionários apresentam habilidades importantes. Ao mesmo tempo, são necessárias melhorias quanto ao trabalho em equipe, contribuições com novas ideias e compartilhamento de conhecimento. Em relação ao Capital Estrutural constatou-se que os funcionários possuem comprometimento com os objetivos e metas estabelecidas. Sobre o Capital Relacional, de maneira geral as relações verticais estão fortalecidas, necessitando desenvolver de forma mais intensa as relações horizontais.

Palavras-chave: Capital Intelectual. Conhecimento. Capital Humano. Capital Estrutural. Capital Relacional.

\section{ABSTRACT}

Intellectual Capital consists of any useful knowledge that a company possesses. The objective of this research was to analyze the relationship between individual Intellectual Capital and collective Intellectual Capital in a chemical firm. The study aims to contribute to the perception of the relationship between individual and collective Intellectual Capital and its possible support to knowledge organizations. To do this, a case study was carried out through data triangulation. The main results show that, with respect to Human Capital, employees present important skills. At the same time, improvements are needed in terms of teamwork, contributions with new ideas and knowledge sharing. Regarding the Structural Capital, it was found that the employees are committed to the established objectives and goals. As for the Relational Capital, in general, vertical relationships are strengthened, but horizontal relationships need to be more intensively developed.

Keywords: Intellectual Capital. Knowledge. Human Capital. Structural Capital. Relational Capital. 


\section{INTRODUÇÃO}

O Capital Intelectual (CI) é assunto cada vez mais pertinente ao âmbito organizacional, levando em conta a busca contínua pelo diferencial competitivo em um mercado extremamente acelerado e internacionalizado. Organizações intensivas em conhecimento que investem em Capital Intelectual se tornam capazes de perceber e desenvolver a aprendizagem como recurso estratégico, criando conhecimento que pode ser processado internamente e utilizado externamente (ALVARENGA-NETO, 2008, SUBRAMANIAM; VENKATRAMAN, 2001, NAHAPIET; GHOSHAL, 1998).

Historicamente, o termo Capital Intelectual se referia a uma forma de mensuração dos recursos intangíveis de uma empresa, que surgiu da necessidade de esclarecer o que a contabilidade não alcança quanto à criação de valor. Atualmente, do ponto de vista estratégico, o Capital Intelectual está relacionado à manutenção do estoque de conhecimento das empresas, bem como sua ampliação, contribuindo decisivamente para a criação de heterogeneidade, tornando-se o principal recurso para a criação de inovação (ENGELMAN et al., 2017 SUBRANIAM; YOUNDT, 2005, AHUJA, 2000; DAVENPORT; PRUSAK, 2003) e, é composto por três dimensões: (a) Capital Humano; (b) Capital Estrutural; (c) Capital Relacional.

Logo, organizações do conhecimento, que investem no Capital Intelectual são consideradas mais inovadoras e propensas a obter melhores desempenhos (JARDON; MATOS, 2009). Assim, o valor atribuído ao Capital Intelectual consiste na utilização de métodos para monitorar, coletar, analisar, promover, explicar e apresentar a dimensão intelectual da empresa com transparência (FIGUEIREDO, 2005; BERTOLLA et al, 2015), e posteriormente utilizá-lo para criação e aprimoramento dos processos e produtos da empresa.

Desta forma, a importância dessa pesquisa se estabelece pelo vínculo entre o sucesso organizacional e o Capital Intelectual indicando que é um tema que necessita de maior compreensão para que seja gerenciado eficazmente (SUBRANIAM; YOUNDT, 2005, AHUJA, 2000, SUBRAMANIAM; VENKATRAMAN, 2001, TSAI; GHOSHAL, 1998). Nota-se que o CI pode ser reconhecido como coletivo ou individual. O coletivo representa os conhecimentos da organização como um todo e o individual relaciona apenas o conhecimento próprio de cada individuo pertencente à empresa. Logo o Capital Intelectual individual (indivíduo específico) pode influenciar no desempenho do Capital Intelectual coletivo (contexto organizacional), e, assim reciprocamente, buscando compreender de que forma essa influência acontece a questão que norteia a pesquisa é: Qual a relação entre o Capital Intelectual individual (CII) e Capital Intelectual coletivo (CIC)?

Através de um estudo de caso (YIN, 2015) utilizando a triangulação de dados por meio de abordagens qualitativas e quantitativas, o presente artigo teve como objetivo principal verificar a relação entre Capital Intelectual individual e Capital Intelectual coletivo na empresa Indusquimy (nome fictício): indústria química de médio porte localizada na região do Vale dos Sinos, Rio Grande do Sul. Este trabalho pretende contribuir na percepção e compreensão da relação entre o Capital Intelectual individual e coletivo e quais as suas possíveis contribuições para as organizações. Poucos estudos têm testado empiricamente a relação entre os recursos humanos das organizações, ou seja, seu capital individual, e o Capital Intelectual coletivo. Além disso, as práticas consideradas nestes estudos ainda não são suficientes para aprimorar os processos voltados ao conhecimento organizacional (CAELLO-MEDINA; LOPEZ-CABRALES; VALLE-CABRERA, 2011, DONATE; PENA; SANCHEZ, 2016, VALE; BRANCO; RIBEIRO, 2016, KIANTO; SAENZ; ARAMBURU, 2017).

Na seção seguinte apresenta-se a base teórica da pesquisa, ou seja, Capital Intelectual nas dimensões: humana, estrutural e relacional, por meio de uma relação entre os aspectos individuais e coletivos. $\mathrm{Na}$ sequência, foram apresentados os procedimentos metodológicos do estudo, bem como os resultados e análises. Por fim, as considerações finais foram descritas. 


\section{CONHECIMENTO: INDIVÍDUAL E COLETIVO}

$\mathrm{Na}$ atualidade, as demandas tecnológicas e de inovação apropriam-se do mercado global, estabelecendo uma diretriz que envolve a busca contínua por conhecimento. Tanto os indivíduos, quanto as organizações transitam em um ambiente de constante necessidade de informação e conhecimento, demandando gestão desses ativos. O conhecimento tornou-se o capital de uma economia desenvolvida, porque surge um novo sistema de poder no lugar do antigo sistema industrial. $\mathrm{O}$ conhecimento supera a informação, da maneira que a informação supera os dados. Com isso, as organizações crescentemente têm necessidade de adquirir conhecimento e aprender a partir de diferentes informações disponíveis (REIS; NODARI; DORION, 2012).

Durante o processo de construção do conhecimento as organizações têm o papel de promover o contexto apropriado para facilitar as atividades de criação de conhecimento do grupo, além disso, simplificar a criação e o acumulo de conhecimento em nível individual (TAKEUCHI; NONAKA, 2008, UVEDA et al, 2014). Para isso, os fatores da cultura organizacional contribuem na capacidade que uma empresa tem para gerir seu conhecimento. Sendo assim, uma cultura colaborativa facilita a troca de conhecimento (CENTENARO; BONEMBERGER; LAIMAR, 2016).

A aquisição do conhecimento em nível individual envolve a capacidade de lidar com novas situações, informações, contextos e eventos, necessitando aproveitar as novas experiências de forma construtiva (TAKEUCHI; NONAKA, 2008). Fleury e Oliveira Jr (2014) consideram que o conhecimento individual implica na habilidade de um indivíduo em responder determinadas situações reais e de realizar certas ações, em vez de apenas reagir de forma irrelevante. De forma similar, Hoss et al, (2010), identificam o conhecimento individual como a capacidade de aplicar a informação em um trabalho distinto, tornando-se tarefa fundamental dos seres humanos e geralmente é alcançada através de percepções, inteligências e habilidades.

Já o conhecimento em nível coletivo é desenvolvido por meio de interações entre indivíduos que es- tão vinculados ao mesmo grupo interno, mas também no convívio entre as empresas (FLEURY; OLIVEIRA JR, 2014). Logo, o conhecimento coletivo é criado e revelado na prática compartilhada entre grupos de trabalho. Apropriar-se do conhecimento que os demais membros da organização possuem caracteriza-se em conhecimento coletivo, possibilitando assim a capacidade de criar novas ideias, multiplicando-as por toda a empresa. Assim, as pessoas constroem, mantêm, melhoram e organizam o conhecimento em torno das rotinas de trabalho, utilizando as aptidões e habilidades como forma de tornar mais eficiente as práticas da organização (FIGUEIREDO, 2005). Para isso, as organizações precisam compreender o valor atribuído ao fator humano, pois suas habilidades e motivações constituem a base do conhecimento (MARQUES; GOMES, 2011).

Assim, o aprendizado se dá de maneira coletiva, e, o desempenho da organização dependerá da sua capacidade para mobilizar e combinar as competências das ações individuais que enriquecerão uma rede coletiva para mobilização na solução de problemas e, até mesmo, nas inovações (UVEDA et al, 2014, CARVALHO, 2012). As organizações inovadoras investem no desenvolvimento do conhecimento individual e coletivo como forma de potencializar seu Capital Intelectual buscando contínua renovação.

\subsection{CAPITAL INTELECTUAL}

O Capital Intelectual consiste na agregação de todo e qualquer conhecimento útil de uma determinada organização. Nas empresas com estratégias bem definidas e foco em inovação, o Capital Intelectual é considerado um dos principais recursos para desenvolver a vantagem competitiva (SUBRANIAM; YOUNDT, 2005, AHUJA, 2000). Esse ativo intelectual possui composição intangível, ou seja, não se pode tocar. Logo, sua gestão torna-se um grande desafio para as empresas.

Campbell e Rahman (2010) afirmam que uma definição consensual e universal de Capital Intelectual é ilusória. No entanto, a maioria dos autores parece concordar que é um conceito multidimensional útil para descrever os ativos de conhecimento de uma empresa e sua dinâmica ao longo do tempo. Para Dean e Kretschmer (2007) o Capital Intelectual está ligado 
à capacidade de uma organização de criar e aplicar sua base de conhecimentos, tendo em essência três características: (a) sua intangibilidade; (b) seu potencial de criação de valor; (c) o efeito do crescimento de práticas coletivas e sinergias.

Diante disso, Figueiredo (2005) ressalta que, apesar de parecer simples definir Capital Intelectual, a sua gestão consiste em uma prática trabalhosa de institucionalizar, a qual requer um novo olhar de gerir a empresa e seus recursos tangíveis e intangíveis. Klein (1998) afirma que o Capital Intelectual envolve a organização como um todo e, apesar disso, sua importância ao nível individual é fundamental, pois mesmo que as organizações possam aprender independentemente de algum indivíduo específico, não podem institucionalizar esse conhecimento sem todos os indivíduos. Logo, o conhecimento é o produto gerado pelos indivíduos (ASSIS, 2005).

Vale, Branco e Ribeiro (2016) buscam conceituar a relação entre CII e CIC, destacando que essa relação tem evoluindo no decorrer dos últimos anos, condicionada, preponderantemente, a situações em que o CI pode ser criado, tanto em nível individual quanto coletivo de forma interdependente. Ou seja, o CIC pode afetar o CII, assim como o CII pode afetar no CIC.

Para identificar a grandeza do CI torna-se imprescindível a mensuração dos seus ativos que estão intrinsecamente ligados à oportunidade de potencializar e gerar benefícios futuros ao empreendimento (ARNOSTI et al, 2011). Porém, a conjuntura atual faz com que se atente principalmente a fatores econômicos visando evidenciar o valor desses ativos no presente. No entanto, Antunes (2007) afirma que esta não é uma percepção geral; talvez seja mais uma questão de gestão e valor organizacional. Isso porque acreditar, mensurar, gerenciar e principalmente valorizar os recursos que conduzem à otimização dos resultados, levando em conta uma dimensão mais ampla que a financeira, é o maior desafio.

Posto isso, é importante destacar as limitações e os benefícios da mensuração deste ativo. Como principais benefícios salientam-se: confirmar as habilidades da organização para atingir seus objetivos, projetar $\mathrm{P} \& \mathrm{D}$, fornecer informações básicas aos programas de reengenharia, suprir programas organizacionais e treinamentos, analisar o valor da em- presa e ampliar sua memória organizacional. E como principais limitações destacam-se: a não existência de um modelo padrão para divulgação de informações, a necessidade de um sistema de informação eficiente em conta do grande número de indicadores, $\mathrm{o}$ alto investimento em sistema de informação e a falta de uma unidade padrão de mensuração (ANTUNES, 2007).

Portanto, a avaliação do CI de uma organização fornece subsídios para fortalecer sua estratégia e identificar as necessidades de melhoria, influenciando diretamente no alcance de seus objetivos. Roos et al. (1997) já assinalavam que a melhor opção para o entendimento do conceito de CI é distinguir suas diferentes dimensões, pois além de ajudar na sua compreensão, permite trazê-lo mais próximo de um nível operacional.

\subsubsection{Composição do Capital Intelectual}

Apesar de não haver consenso sobre os elementos que compõem o CI, grande parte dos autores, como Edvinsson e Malone (1998), Stewart (1998), Coser (2012), Costa, Fernández-Jardón e Figueroa Dorrego (2014), Dumay (2016) sugerem que a estrutura do Capital Intelectual é composta por três componentes básicos:

a) Capital Humano: "pessoas", "competências dos colaboradores" (COSER, 2012).

b) Capital Estrutural: "capital organizacional", "estrutura interna” (COSER, 2012).

c) Capital Relacional: "relações verticais", "relações horizontais” (COSTA, FERNÁNDEZ-JARDÓN, FIGUEROA DORREGO 2014).

\subsubsection{Capital Humano}

No Capital Humano podem ser consideradas todas as contribuições e resultados gerados pelos indivíduos dentro das organizações, por meio de suas competências, ou seja, seus conhecimentos, suas habilidades e suas atitudes. O ser humano pode considerado como capital, pois possui capacidades de gerar bens e serviços, através de sua força de trabalho e conhecimento, constituindo-se em importante fonte de acumulação e crescimento econômico (ANTUNES, 2007). O Capital Humano é fonte de inovação 
e renovação, podendo ou não se tornar um modo de pensar coletivo/empresarial, pois abrange ações de compartilhamento e transmissão de conhecimento
(FIGUEIREDO, 2005). O Quadro 1 a seguir pretende evidenciar fatores fundamentais deste ativo.

Quadro 1 Indicadores de Capital Humano

\begin{tabular}{l|l|l}
\hline \multicolumn{1}{c|}{ Elementos } & \multicolumn{1}{|c|}{ Indicadores } & \multicolumn{1}{c}{ Referências } \\
\hline Conhecimentos & $\begin{array}{l}\text { Funcionários conhecem e compreendem os produtos e processos de trabalho } \\
\text { da empresa. (CH1). } \\
\text { Funcionários tem conhecimento para realizar seu trabalho adequadamente } \\
\text { influenciando no resultado da empresa (CH2). }\end{array}$ & $\begin{array}{l}\text { Costa, Fernández-Jardón e Figueroa } \\
\text { Dorrego (2014) e Delgado-Verde } \\
\text { et al (2016). }\end{array}$ \\
\hline Habilidades & $\begin{array}{l}\text { Funcionários têm habilidades amplamente qualificadas (CH3). } \\
\text { Funcionários têm habilidades a nível individual especificas para o cargo exercido } \\
\text { (CH4). }\end{array}$ & $\begin{array}{l}\text { Delgado-Verde et al (2016), Engel- } \\
\text { man (2016), Engelman et al. (2017) }\end{array}$ \\
\hline Atitudes & $\begin{array}{l}\text { Funcionários demonstram interesse e desenvolvem novas ideias e conhecimen- } \\
\text { to (CH5). } \\
\text { Funcionários frequentemente desenvolvem trabalho em equipe (CH6). } \\
\text { Funcionários cooperam e compartilham o conhecimento com o coletivo (CH7). }\end{array}$ & $\begin{array}{l}\text { Costa, Fernández-Jardón e Figueroa } \\
\text { Dorrego (2014), Delgado-Verde et al } \\
\text { (2016), Engelman (2016), Engelman }\end{array}$ \\
& & \begin{tabular}{l} 
(2017) \\
\hline
\end{tabular}
\end{tabular}

Fonte: Elaborado pelos autores

Quanto mais qualificado o Capital Humano de uma organização, melhores resultados ela poderá alcançar em termos de CI. Costa, Fernández-Jardón e Figueroa Dorrego (2014) ressaltam que para isso a empresa precisa de pessoas que sabem integrar, selecionar, partilhar e enriquecer informações para criar a compreensão e assimilação do conhecimento, transformando os processos de inovação. Ainda sobre isso, Engelman et al. (2017) afirma que são os indivíduos e o Capital Humano que está associado a eles que dão origem ao aumento da capacidade de absorver e implantar novos conhecimentos nas rotinas de trabalho, combinando ideias antes desconectadas.

O Capital Humano está vinculado à capacidade e ao comprometimento dos indivíduos junto aos objetivos e estratégias da organização. A sessão seguinte apresenta outra composição do Capital Intelectual: a dimensão do Capital Estrutural.

\subsubsection{Capital Estrutural}

No âmbito organizacional, como o próprio nome já diz, o Capital Estrutural é visto como estruturante e abrange a base de apoio organizacional. Dentre os demais elementos, este é o que efetivamente se constitui como propriedade da empresa.
Nesse sentido, Edvinsson e Malone (1998) consideram o Capital Estrutural como a infraestrutura que apoia o Capital Humano. Ele abrange os sistemas que são utilizados para transmitir e armazenar conhecimento intelectual, como banco de dados, imagem da empresa, conceitos organizacionais e documentos. Antunes (2007) sugere que esse capital se constitui em toda a capacidade organizacional que apoia a produtividade dos empregados como, por exemplo, os equipamentos de informática que garantem maior facilidade no armazenamento de conhecimentos e troca de informações.

Além disso, conforme Cabrita e Bontis (2008) o Capital Estrutural pode ser visto como as ferramentas e a arquitetura que uma organização fornece para retenção e transferência do conhecimento ao longo das atividades. Arnosti et al (2011) indicam que a cultura organizacional, filosofia do negócio, valores e atitudes praticadas são aspectos que complementam esse capital. Costa, Fernández-Jardón e Figueroa Dorrego (2014) compreendem a cultura como elemento implícito e que pode ter impacto expressivo para um clima de aprendizagem e de promoção da criatividade nas organizações. Com intuito de evidenciar os fatores fundamentais deste ativo apresenta-se o Quadro 2. 
Quadro 2 Elementos e Indicadores do Capital Estrutural

\begin{tabular}{l|l|l}
\hline \multicolumn{1}{c|}{ Elementos } & \multicolumn{1}{c|}{ Indicadores } & \multicolumn{1}{c}{ Referências } \\
\hline Estrutura interna & $\begin{array}{l}\text { As tecnologias utilizadas pela empresa na rotina de trabalho são uteis para o } \\
\text { acumulo de conhecimento (CE1). } \\
\text { Há sistemas de dados que facilitam a execução do trabalho (CE2). }\end{array}$ & $\begin{array}{l}\text { Delgado-Verde et al (2016) e Costa, } \\
\text { Fernández-Jardón, Figueroa } \\
\text { Dorrego (2014) }\end{array}$ \\
\hline $\begin{array}{l}\text { Capital } \\
\text { organizacional }\end{array}$ & $\begin{array}{l}\text { Funcionários identificam-se com a estratégia da empresa (CE3). } \\
\text { A maior parte dos conhecimentos da empresa encontra-se em manuais, base de } \\
\text { dados, entre outros (CE4). } \\
\text { A cultura da nossa empresa (histórias, rituais) tem ideias valiosas, formas de fazer } \\
\text { negócio, entre outros (CE5). }\end{array}$ & $\begin{array}{l}\text { Coser (2012), Engelman et al. (2017) } \\
\text { e Engelman (2016). }\end{array}$ \\
\hline
\end{tabular}

Fonte: Elaborado pelos autores

Esse capital transforma o conhecimento dos indivíduos em ativo da organização, por meio da melhoria contínua, compartilhamento de criatividade e da experiência; obtendo assim maior agilidade na distribuição do conhecimento, minimizando o retrabalho, aumentando o conhecimento coletivo, reduzindo o tempo de espera e ampliando a produtividade (SCHMIDT; SANTOS, 2009).

Antunes (2007) afirma que por meio do Capital Estrutural podem-se identificar aspectos importantes no âmbito organizacional, como diferenças entre criações de patentes, desenvolvimento de novos designs e produtos; gerando maior vantagem competitiva. Engelman et al. (2017) ressalta que mesmo o cérebro humano sendo considerada principal fonte de conhecimento é através do Capital Estrutural, pelos seus bancos de dados, processos, cultura e estrutura que esse conhecimento é institucionalizado e codificado.

Tendo em vista a importância do Capital Estrutural, nota-se que sua atribuição compõe tanto questões relacionadas ao apoio organizacional, quanto à estrutura interna da empresa e bases tecnológicas. Ainda sobre a composição do CIna subseção seguinte, apresenta-se a dimensão do Capital Relacional.

\subsubsection{Capital Relacional}

Os vínculos e relacionamentos da organização com o ambiente externo compreendem o Capital Relacional. Essas interações influenciam em seus resultados e na reputação perante a sociedade.

O Capital Relacional compreende o valor dos relacionamentos de uma empresa com as pessoas com que faz negócios (FIGUEIREDO, 2005). A conexão entre a empresa e seus clientes e fornecedores, por exemplo, agregam valor por meio da fidelidade, qualidade, velocidade e mercados melhorados (PACHECO, 2005).

Para Engelman et al. (2017), o Capital Relacional está relacionado à interação entre indivíduos e busca aprimorar a troca de informações e o compartilhamento de ideias, reforçando o conhecimento existente e permitindo que novos conhecimentos circulem pela organização, dando origem, principalmente, à inovação.

O relacionamento de uma empresa com seus clientes é distinto das relações mantidas internamente, assim, sua importância é fundamental para o valor da empresa (EDVINSSON; MALONE, 1998). O Quadro 3 evidencia os fatores fundamentais deste ativo.

Quadro 3 Elementos e Indicadores do Capital Relacional.

\begin{tabular}{l|l|l}
\hline \multicolumn{1}{c|}{ Elementos } & \multicolumn{1}{c|}{ Indicadores } & \multicolumn{1}{c}{ Referências } \\
\hline $\begin{array}{l}\text { Relações } \\
\text { verticais }\end{array}$ & $\begin{array}{l}\text { A empresa busca identificar e estabelecer um relacionamento de lealdade com } \\
\text { seus clientes (CR1). } \\
\text { A empresa busca trabalhar considerando a necessidade do cliente (CR2). } \\
\text { A empresa possui parcerias estabelecidas com seus fornecedores (CR3). }\end{array}$ & $\begin{array}{l}\text { Costa, Fernández-Jardón e Figueroa } \\
\text { Dorrego (2014), Engelman et al. } \\
\text { (2017), Engelman (2016) e Delgado- } \\
\text {-Verde et al (2016). }\end{array}$ \\
\hline $\begin{array}{l}\text { Relações } \\
\text { horizontais }\end{array}$ & $\begin{array}{l}\text { Existem relações positivas com parceiros e concorrentes para troca de informa- } \\
\text { ções convenientes (CR4). }\end{array}$ & $\begin{array}{l}\text { Delgado-Verde et al (2016) e Costa, } \\
\text { Fernández-Jardón e Figueroa Dor- } \\
\text { rego (2014). }\end{array}$ \\
\hline
\end{tabular}

Fonte: Elaborado pelos autores 
A análise e reanálise da cadeia de valor do setor no qual atua é relevante a fim da organização atualizar-se com informações importantes, pois o Capital Relacional aumenta quando a organização, seus clientes e fornecedores aprendem uns com os outros e engajam-se ativamente em tornar suas intenções mais informais (SCHMIDT; SANTOS, 2009).

Delgado-Verde et al (2016) reforçam o fato de que as relações horizontais geram maior confiabilidade para empresa, desenvolvendo a capacidade de compreender e assimilar o novo, melhorando seus resultados através de uma perspectiva inovadora. Diante disso Costa, Fernández-Jardón e Figueroa Dorrego (2014) afirmam que já as relações horizontais têm impacto direto na sua capacidade inovadora de produto e desempenho.

A sessão seguinte apresenta o método para a coleta e análise dos dados da pesquisa.

\section{PROCEDIMENTOS METODOLÓGICOS}

Esse trabalho teve como objetivo geral analisar a relação entre as dimensões individual e coletiva do CI na Indusquimy. Essa empresa é considerada competitiva e inovadora em seu setor de atuação, conforme registros documentais da organização. $\mathrm{O}$ CII será mensurado pela percepção individual dos funcionários e o CIC será mensurado pela percepção dos gestores sobre a empresa como um todo. Adotou-se um estudo de caso descritivo, pois permite ao investigador um aprofundamento sobre o fenômeno estudado, revelando aspectos difíceis de serem observados de outra forma. O estudo de caso fornece uma visão holística sobre os acontecimentos do cotidiano, destacando-se pelo caráter de investigação empírica de fenômenos contemporâneos e pela triangulação de variadas fontes de informação (YIN, 2015). A pesquisa caracterizou-se tanto como quantitativa e qualitativa.

Os critérios para a seleção da empresa pesquisada foram: a) atuar em setor no qual o desenvolvimento de tecnologia seja fundamental, b) estar posicionada como empresa inovadora e estar entre os principais players do setor, para que o CI seja relevante para a competitividade da organização; c) atuar há pelo menos dez anos no mercado, para que o CI possa ter sido desenvolvido; e d) ser empresa de médio ou grande porte, para que seja possível a realização dos testes estatísticos.

A empresa selecionada é uma indústria química de médio porte da região do Vale dos Sinos, a qual atende tanto o mercado nacional quanto o mercado internacional. Ela se descreve como tendo o compromisso de suprir a necessidade de seus clientes com produtos altamente tecnológicos e colocando à disposição destes um atendimento técnico de qualidade. Atuando tanto no mercado nacional quanto internacional, exportando para mais de vinte países em quatro continentes, a empresa intitula-se alinhada com as tendências de tecnologia, moda e sustentabilidade. Atualmente possui vinte e seis anos desde a fundação em 1990 e tem cento e quinze funcionários, dentre estes 12 gestores, divididos entre a matriz e duas filiais. A matriz está localizada na cidade de Portão, Rio Grande do Sul, na qual está instalada a área produtiva, laboratório de desenvolvimento e expedição. Com relação às filiais, uma está localizada na mesma cidade, a qual conta com instalações da área administrativa, vendas, expedição e laboratórios técnicos e a outra, de menor tamanho, está localizada na cidade de Franca, São Paulo, e conta com a área de vendas e expedição.

A empresa possui um capital humano construído com base em uma relação duradoura visto que a maioria dos membros possui mais de dez anos de atuação na empresa, mantendo o conhecimento internalizado. Sobre a estrutura disponível a inserção de novas tecnologias de gestão e produtos nos últimos anos vem sendo aspecto positivo para um posicionamento mais competitivo da empresa no mercado.

Em relação aos instrumentos de coleta de dados, foram elaborados dois questionários estruturados similares, com questões sobre o nível individual (percepção dos funcionários sobre eles mesmos) e sobre o nível coletivo (percepção dos gestores sobre toda a empresa). Os indicadores utilizados para a construção dos instrumentos foram desenvolvidos a partir dos quadros apresentados na seção de embasamento teórico, contemplando as dimensões de Capital Humano, Capital Estrutural e Capital Relacional. Os indicadores foram construídos com base em Costa, Fernández-Jardón e Figueroa Dorrego (2014), Coser (2012), Delgado-Verde et al (2016) e Engelman et al. 
(2017), e validados por dois especialistas na área. A escala utilizada para pesquisa foi do tipo Likert com variação de sete pontos desde "discordo totalmente" até "concordo totalmente".

O questionário foi enviado para todos os 115 colaboradores da empresa. Desses, 86 questionários retornaram respondidos, perfazendo uma taxa de resposta de 75\%, o que de acordo com Malhotra (2012) pode ser considerada uma taxa de retorno significativa. Além disso, com intuito de aprofundar as análises foram realizadas entrevistas semiestruturadas com três gestores da empresa. Essas entrevistas foram agendadas através de contato telefônico e realizadas em sala de reunião própria da empresa, com duração média de uma hora cada. Os critérios para seleção dos gestores foram: tempo de empresa de no mínimo de cinco anos e estar exercendo cargo de gestão na empresa por pelo menos três anos, para conhecer a realidade da mesma. Além disso, a fim de contemplar as especificidades com o tema de pesquisa optou-se em selecionar o gestor do setor de recursos humanos, o qual possui relação com o Capital Humano; o gestor do setor de pesquisa e desenvolvimento (P\&D) de produtos, o qual possui relação com o Capital Estrutural; e o gestor do setor de vendas, o qual possui relação com o Capital Relacional da empresa.

Foram também utilizados documentos internos como: relatórios, site da própria empresa, indicadores da área de recursos humanos e sistema interno de dados. Em relação às pesquisas documentais Gil (2008) afirma que as fontes se valem de materiais que ainda não receberam tratamento analítico. De forma complementar, utilizou-se a técnica observacional que para Prodanov e Freitas (2013), é um método muito utilizado nas ciências sociais e apresenta aspectos importantes, pois possibilita um alto grau de precisão.

Em relação aos procedimentos de análise dos dados coletados, foi utilizada a análise de conteúdo que para Zanella (2009), demanda de materiais escritos, provenientes de textos, transcrição de entrevistas ou registros. Dessa forma, os dados coletados foram comparados com as categorias do referencial teórico. As análises estatísticas foram através do teste $t$ de amostras independentes para verificar se existe diferença significativa $(\mathrm{p}<0,05)$ nas médias entre gestores e funcionários (HAIR et al., 2005). O programa utilizado para esta análise foi o SPSS versão 23.

\section{RESULTADOS E ANÁLISE}

A Tabela 1 apresenta as características da amostra com a descrição do perfil dos funcionários e gestores.

Os dados coletados na pesquisa foram analisados a partir das três dimensões do Capital Intelectual apresentadas, especificamente, na sequência.

\subsection{Capital Humano}

A descrição da análise relacionada à dimensão Capital Humano $(\mathrm{CH})$ desenvolveu-se com base na comparação da percepção dos funcionários (nível individual) e dos gestores (nível coletivo) conforme a Tabela 2.

Utilizando-se teste $t$, nenhuma das afirmativas da Tabela 2 apresenta variação significativa $(p<0,05)$ na comparação da percepção entre gestores (coletivo) e funcionários (individual). Nas questões relacionadas ao conhecimento em relação aos produtos $(\mathrm{CH} 1)$ e aos processos ( $\mathrm{CH} 2)$, nota-se que tanto os gestores, quanto os funcionários têm percepções semelhantes. Schmidt e Santos (2009) salientam que as empresas precisam utilizar o conhecimento dos funcionários e, quanto maior esses conhecimentos, maior torna-se o valor agregado ao seu Capital Humano. Neste sentido, apesar do nível de conhecimento ser consideravelmente alto, este pode ser aprimorado em relação aos produtos, já que de acordo com Takeuchi e Nonaka (2008), o aprendizado consistirá em dois tipos de atividade: a) obtenção do know-how a fim de resolver problemas específicos baseados em premissas específicas; b) estabelecimento de novas premissas expressas por novos paradigmas, esquemas, modelos mentais ou perspectivas, cujo objetivo é anular as premissas existentes.

Sobre o elemento habilidades, a afirmativa que está relacionada à influência individual no contexto coletivo $(\mathrm{CH} 3)$ apresenta concordância significativa na percepção dos gestores $(6,45)$ e funcionários $(6,45)$; assim como a afirmativa sobre a importância das habilidades individuais para o cargo que executa (CH4) na percepção dos gestores $(6,55)$ e funcionários $(6,34)$, ambos com médias altas, superior a 6 pontos. Essas concordâncias corroboram o proposto por Takeuchi e Nonaka, (2008), Engelman et al. 


\begin{tabular}{|c|c|c|c|c|}
\hline \multirow[b]{2}{*}{ VARIÁVEIS } & \multicolumn{2}{|c|}{ Funcionários } & \multicolumn{2}{|c|}{ Gestores } \\
\hline & FA & $\%$ & FA & $\%$ \\
\hline $\begin{array}{l}\text { SEXO } \\
\text { Feminino } \\
\text { Masculino }\end{array}$ & $\begin{array}{l}16 \\
59\end{array}$ & $\begin{array}{l}21,3 \% \\
78,7 \%\end{array}$ & $\begin{array}{l}5 \\
6\end{array}$ & $\begin{array}{l}45,5 \% \\
54,5 \%\end{array}$ \\
\hline $\begin{array}{l}\text { UNIDADE } \\
\text { Matriz } \\
\text { Filial - RS } \\
\text { Filial - SP }\end{array}$ & $\begin{array}{c}43 \\
29 \\
3\end{array}$ & $\begin{array}{c}57,3 \% \\
38,7 \% \\
4,0 \%\end{array}$ & $\begin{array}{l}4 \\
7 \\
0\end{array}$ & $\begin{array}{c}36,4 \% \\
63,6 \% \\
0,0 \%\end{array}$ \\
\hline $\begin{array}{l}\text { SETOR } \\
\text { Operacional } \\
\text { Técnico } \\
\text { Administrativo }\end{array}$ & $\begin{array}{l}42 \\
21 \\
12\end{array}$ & $\begin{array}{l}56,0 \% \\
28,0 \% \\
16,0 \%\end{array}$ & $\begin{array}{l}3 \\
3 \\
5\end{array}$ & $\begin{array}{l}27,3 \% \\
27,3 \% \\
45,5 \%\end{array}$ \\
\hline $\begin{array}{l}\text { ESTADO CIVIL } \\
\text { Solteiro } \\
\text { Casado }\end{array}$ & $\begin{array}{l}26 \\
49\end{array}$ & $\begin{array}{l}34,7 \% \\
65,3 \%\end{array}$ & $\begin{array}{c}1 \\
10\end{array}$ & $\begin{array}{c}9,1 \% \\
90,9 \%\end{array}$ \\
\hline $\begin{array}{l}\text { ESCOLARIDADE } \\
\text { Ensino fundamental Incompleto/completo } \\
\text { Ensino médio Incompleto/completo } \\
\text { Ensino superior incompleto } \\
\text { Ensino superior completo }\end{array}$ & $\begin{array}{c}16 \\
41 \\
9 \\
9\end{array}$ & $\begin{array}{l}21,3 \% \\
57,4 \% \\
12,0 \% \\
12,0 \%\end{array}$ & $\begin{array}{l}0 \\
5 \\
0 \\
6\end{array}$ & $\begin{array}{c}0,0 \% \\
45,5 \% \\
0,0 \% \\
54,5 \%\end{array}$ \\
\hline
\end{tabular}

Fonte: Elaborado pelos autores

Tabela 2 Indicadores do Capital Humano

\begin{tabular}{|c|c|c|c|c|c|c|}
\hline E & Indicadores & Nível & No & Média & $\begin{array}{l}\text { Desvio } \\
\text { Padrão }\end{array}$ & $\begin{array}{l}\text { Valor } t \\
\text { GL } \\
\text { Sig. }\end{array}$ \\
\hline$C$ & $\begin{array}{l}\text { Você conhece os produtos que a empresa desenvolve (CH1). } \\
\text { Os funcionários conhecem os produtos que a empresa desenvolve (CH1). }\end{array}$ & $\begin{array}{l}\text { Func. } \\
\text { Gest. }\end{array}$ & $\begin{array}{l}71 \\
11\end{array}$ & $\begin{array}{l}4,75 \\
5,64\end{array}$ & $\begin{array}{l}1,969 \\
1,120\end{array}$ & $\begin{array}{l}-1,458 \\
80,0,149\end{array}$ \\
\hline$C$ & $\begin{array}{l}\text { Você compreende os processos de trabalhos da empresa }(\mathrm{CH} 2) \text {. Os funcio- } \\
\text { nários compreendem os processos de trabalho da empresa }(\mathrm{CH} 2)\end{array}$ & $\begin{array}{l}\text { Func. } \\
\text { Gest. }\end{array}$ & $\begin{array}{l}74 \\
11\end{array}$ & $\begin{array}{l}5,30 \\
6,18\end{array}$ & $\begin{array}{l}1,893 \\
1,079\end{array}$ & $\begin{array}{l}-1,509 \\
83 \\
0,135\end{array}$ \\
\hline $\mathrm{H}$ & $\begin{array}{l}\text { Você acredita que seu trabalho influencia os resultados da empresa }(\mathrm{CH} 3) \text {. } \\
\text { Você acredita que o trabalho de alguns funcionários influência no resultado } \\
\text { da empresa ( } \mathrm{CH} 3)\end{array}$ & $\begin{array}{l}\text { Func. } \\
\text { Gest. }\end{array}$ & 73 & 6,45 & 1,225 & $\begin{array}{l}-, 009 \\
17,57 \\
0,993\end{array}$ \\
\hline $\mathrm{H}$ & $\begin{array}{l}\text { Suas habilidades Individuais são importantes para o cargo que executa }(\mathrm{CH} 4) \\
\text { Os funcionários de sua equipe têm habilidades individuais que são indispen- } \\
\text { sáveis para o cargo que executam ( } \mathrm{CH} 4)\end{array}$ & $\begin{array}{l}\text { Func. } \\
\text { Gest. }\end{array}$ & $\begin{array}{l}71 \\
11\end{array}$ & $\begin{array}{l}6,34 \\
6,55\end{array}$ & $\begin{array}{l}1,183 \\
0,820\end{array}$ & $\begin{array}{c}-, 729 \\
17,2230,476\end{array}$ \\
\hline A & $\begin{array}{l}\text { Você tem interesse em contribuir com novas ideias (CH5) } \\
\text { Os funcionários contribuem com sugestão de ideias para a empresa ( } \mathrm{CH} 5)\end{array}$ & $\begin{array}{l}\text { Func. } \\
\text { Gest. }\end{array}$ & $\begin{array}{l}71 \\
11\end{array}$ & $\begin{array}{l}5,80 \\
5,18\end{array}$ & $\begin{array}{l}1,887 \\
1,940\end{array}$ & $\begin{array}{c}, 991 \\
13,1060,339\end{array}$ \\
\hline A & $\begin{array}{l}\text { Você desenvolve trabalho em equipe (CH6) } \\
\text { No geral, os funcionários desenvolvem trabalho em equipe }(\mathrm{CH} 6)\end{array}$ & $\begin{array}{l}\text { Func. } \\
\text { Gest. }\end{array}$ & $\begin{array}{l}73 \\
11\end{array}$ & $\begin{array}{l}5,82 \\
4,82\end{array}$ & $\begin{array}{l}1,531 \\
1,991\end{array}$ & $\begin{array}{c}1,602 \\
11,8480,135\end{array}$ \\
\hline$A$ & $\begin{array}{l}\text { Você compartilha conhecimentos com os colegas }(\mathrm{CH} 7) \\
\text { Existe compartilhamento de conhecimento entre colegas de trabalho }(\mathrm{CH} 7)\end{array}$ & $\begin{array}{l}\text { Func } \\
\text { Gest. }\end{array}$ & $\begin{array}{l}74 \\
11\end{array}$ & $\begin{array}{l}5,81 \\
5,00\end{array}$ & $\begin{array}{l}1,611 \\
2,000\end{array}$ & $\begin{array}{c}1,284 \\
12,0060,223\end{array}$ \\
\hline
\end{tabular}

Legenda: $\mathrm{E}=$ Elemento, $\mathrm{C}=$ Conhecimento, $\mathrm{H}=$ Habilidade, $\mathrm{A}=$ Atitude.

Fonte: Elaborado pelos autores 
(2017) dentre outros teóricos que afirmam que são os indivíduos e o Capital Humano associado a eles que dão origem ao aumento da capacidade de absorver e implantar novos conhecimentos nas organizações, combinando ideias antes desconectadas. Percebe-se assim, que os conhecimentos individuais e coletivos nessa dimensão estão, relativamente, desenvolvidos e alinhados na empresa.

Esse aspecto também foi questionado nas entrevistas com os gestores, no qual todos concordaram que existe a influência individual no contexto coletivo. Os gestores também salientam o fato de que, em alguns casos, a contribuição individual interfere diretamente nos resultados da empresa, conforme afirma a gestora de vendas: "[...] existem pessoas chaves que tem grandes ideias e influenciam nos resultados [...] são pessoas que saem na frente e tem um diferencial [...]". Assim, na empresa Indusquimy, os resultados indicam que as pessoas acreditam ter as habilidades individuais necessárias para os cargos que exercem na empresa, e que estas afetam diretamente os resultados coletivos.

Nos indicadores relacionados às atitudes de apresentar novas ideias (CH5) e compartilhar conhecimento com colegas (CH7), apresentam-se índices relativamente altos com uma variação de 5 a 5,82 pontos. Nesse sentido, esses resultados podem ser decorrentes dos pontos positivos do Capital Humano citados pelos gestores nas entrevistas em relação aos funcionários, tais como: são esforçados, possuem comprometimento acima da média, desenvolvem bom relacionamento e executam seu trabalho com qualidade. Costa, Fernández-Jardón, Figueroa Dorrego (2014) ressaltam que a empresa necessita de indivíduos que saibam integrar, selecionar, partilhar e enriquecer informações para criar a compreensão e o conhecimento transformando-os em inovação. Entretanto, se percebe resultados levemente menores na percepção dos gestores, apontando oportunidade para aprimoramento. Isto pode se dever ao fato de que, conforme corrobora Reis, Nodari e Dorion (2014), a construção por parte dos gestores em relação ao aprimoramento deve seguir um continuum apoiando e facilitando os funcionários a adquirirem e compartilharem o conhecimento criando organizações voltadas para o desenvolvimento ininterrupto.
Já em relação à afirmativa $\mathrm{CH} 6$, os gestores concordam em grau menor que os funcionários $(4,82 \mathrm{e}$ 5,82 , respectivamente) sobre o desenvolvimento de trabalho em equipe. Essa percepção relativamente menor também foi identificada nas entrevistas com os gestores; conforme cita o gestor de $\mathrm{P} \& \mathrm{D}$ “[... não existe muito o senso de equipe, não falo apenas em equipe de setor, mas sim, uma visão mais ampla [...] hoje em dia, cada setor pensa em apenas resolver o seu problema, não possuindo uma visão mais global [...]". Mesmo que o teste de média não tenha apontado que esta diferença seja significativa, os resultados qualitativos indicam que torna-se fundamental alinhar esse entendimento e aprimorar as relações, para aperfeiçoar o trabalho em equipe entre os setores e da empresa como um todo.

Além disso, alguns indicadores da área de recursos humanos foram analisados para complementar a análise da dimensão Capital Humano. Os índices do setor não apresentaram qualquer resultado que contrariasse esta percepção, como por exemplo, em relação à rotatividade. Nos últimos seis meses ocorreu o desligamento de apenas três funcionários e a contratação de seis novos, indicando que não houve grande perda de conhecimentos individuais e que prejudicasse o conhecimento coletivo.

\subsection{Capital Estrutural}

A descrição da análise relacionada à dimensão Capital Estrutural (CE) seguiu a mesma forma de apresentação dos dados do Capital Humano conforme a Tabela 3.

Em relação às afirmativas de modo geral, apenas a afirmativa CE1 mostra variação significativa $(p<0,05)$ na comparação da percepção de gestores e funcionários. Uma possível justificativa para essa diferença no resultado é que o perfil dos funcionários em sua maioria encontra-se no setor operacional, o qual não utiliza de forma constante de artefatos como e-mail, planilhas e Skype na rotina de trabalho. Por outro lado, os gestores identificam a utilização dessas tecnologias de forma mais constante. Entretanto, não foram realizadas questões sobre as tecnologias da área da produção, indicando que é um tema que precisa ser melhor investigado. 
Tabela 3 Indicadores do Capital Estrutural

\begin{tabular}{|c|c|c|c|c|c|c|}
\hline $\mathbf{E}$ & Indicadores & Nível & No & Média & $\begin{array}{l}\text { Desvio } \\
\text { Padrão }\end{array}$ & $\begin{array}{l}\text { Valor } t \\
\text { GL } \\
\text { Sig. }\end{array}$ \\
\hline El & $\begin{array}{l}\text { A empresa utiliza outras tecnologias (e-mail, planilhas, Skype, etc.) úteis na } \\
\text { rotina de trabalho (CE1) }\end{array}$ & $\begin{array}{l}\text { Func } \\
\text { Gestor }\end{array}$ & $\begin{array}{l}68 \\
11\end{array}$ & $\begin{array}{l}5,46 \\
6,73\end{array}$ & $\begin{array}{l}2,076 \\
0,647\end{array}$ & $\begin{array}{l}-2,005 \\
77 \\
0,048\end{array}$ \\
\hline $\mathrm{El}$ & $\begin{array}{l}\text { A empresa utiliza um sistema de dados (programas e banco de arquívos) } \\
\text { que facilita a execução do trabalho (CE2) }\end{array}$ & $\begin{array}{l}\text { Func } \\
\text { Gestor }\end{array}$ & $\begin{array}{l}71 \\
11\end{array}$ & $\begin{array}{l}4,75 \\
6,00\end{array}$ & $\begin{array}{l}2,116 \\
1,095\end{array}$ & $\begin{array}{c}-1,588 \\
14,5380,134\end{array}$ \\
\hline $\mathrm{El}$ & $\begin{array}{l}\text { A maioria das informações/conhecimentos da empresa encontra-se regis- } \\
\text { trados em banco de dados, manuais, etc. (CE3) }\end{array}$ & $\begin{array}{l}\text { Func } \\
\text { Gestor }\end{array}$ & $\begin{array}{l}64 \\
11\end{array}$ & $\begin{array}{l}4,81 \\
5,45\end{array}$ & $\begin{array}{l}1,991 \\
1,916\end{array}$ & $\begin{array}{c}-1,021 \\
13,9780,325\end{array}$ \\
\hline $\mathrm{CO}$ & $\begin{array}{l}\text { Você identifica-se com a estratégia (objetivos, metas e forma de atuação) da } \\
\text { empresa. (CE4) } \\
\text { Os Funcionários identificam-se com a estratégia (objetivos, metas e forma } \\
\text { de atuação) da empresa. (CE4) }\end{array}$ & $\begin{array}{l}\text { Func } \\
\text { Gestor }\end{array}$ & 69 & 4,96 & 1,913 & $\begin{array}{c}-, 367 \\
13,4890,719\end{array}$ \\
\hline $\mathrm{CO}$ & $\begin{array}{l}\text { A cultura da nossa empresa (missão, visão, histórias, jeito de fazer as coisas } \\
\text { na empresa) contribui com a realização dos objetivos e sucesso organizacio- } \\
\text { nal (CE5) }\end{array}$ & $\begin{array}{l}\text { Func } \\
\text { Gestor }\end{array}$ & $\begin{array}{l}67 \\
11\end{array}$ & $\begin{array}{l}4,69 \\
5,64\end{array}$ & $\begin{array}{l}2,039 \\
1,804\end{array}$ & $\begin{array}{c}-1,588 \\
14,5380,134\end{array}$ \\
\hline
\end{tabular}

Legenda: $\mathrm{E}=$ Elemento, $\mathrm{El}=$ Estrutura interna, $\mathrm{CO}=$ Capital organizacional.

Fonte: Elaboração própria.

Referente às afirmativas relacionadas à estrutura interna pertinente a utilização sistema de dados (CE2) e forma de registros de informações (CE3), ambos os níveis de concordância relativamente altos, com média variando entre 4,75 e 6 pontos. Antunes (2007) considera esse capital como toda a capacidade organizacional que apoia a produtividade dos empregados. Nesse sentido, um aspecto positivo no comparativo dessas afirmativas com os questionamentos realizados nas entrevistas é a existência de uma tendência de aumento significativo e positivo em relação a esses indicadores, já que está se trabalhando na reestruturação do sistema informatizado da empresa, conforme explica a gerente de vendas "[...] a inclusão do novo sistema se comparado com o anterior, melhorou muito e continua buscando melhorar. Estamos trabalhando em cima de programação na fábrica com matéria prima, aperfeiçoamento de estoque, percebo que estão vindo coisas boas por aí [...]"

Sobre essa restruturação do sistema, através da análise de documentos e arquivos da empresa constata-se que; o antigo modelo utilizado desde 1994 (executados em MS-DOS/em disco) foi sendo substituído gradativamente desde 2011 pelo novo modelo, e atualmente todos os setores são usuários deste sistema e a perspectiva era iniciar 2017 com ele $100 \%$ implementado nas áreas. Sobre isso, o gestor de P\&D afirma que "[...] o sistema melhorou muito, mas ainda tem muito que melhorar. Deve-se investir mais para torna-lo mais amplo possível e a partir disso estimular cada vez mais a troca de informações [...]". Nesse contexto, Engelman et al. (2017) observa que mesmo o cérebro humano sendo considerada principal fonte de conhecimento, é através do Capital Estrutural que esse conhecimento é institucionalizado e codificado pelos seus bancos de dados, processos, cultura e estrutura. Esses resultados comparados com a revisão da literatura indicam que as atualizações que a empresa vem realizando contribuem de forma positiva.

Nas afirmativas relacionadas ao capital organizacional pertinente a identificação dos funcionários com as estratégias da empresa (CE4), os funcionários $(4,96)$ e os gestores $(5,18)$ possuem percepções em níveis similares de concordância, assim como na afirmativa relacionada à cultura da empresa (CE5) que apresentou média de 4,69 entre os funcionários e de 5,64 entre os gestores. Logo, Costa, FernándeZ-Jardón, Figueroa Dorrego (2014) compreendem a cultura como elemento implícito e que pode ter impacto expressivo para um clima de aprendizagem e de promoção da criatividade e, apesar de não serem mal avaliados, estes itens apontaram índices um pouco abaixo em relação a outros indicadores. A 
partir da observação, verificou-se que a empresa não possui missão e visão descritas oficialmente, o que pode justificar esse índice menor. Se as estratégias e a cultura de uma empresa não estão claras, o ambiente pode tornar-se inadequado para o desenvolvimento dos funcionários, para aprimoramento de processo, podendo prejudicar a inovação e o desempenho organizacional. Neste sentido, estratégia e cultura precisam de uma atenção especial e sugere-se a definição destes aspectos pela empresa, desenvolvendo a identidade organizacional e fortalecendo os propósitos do negócio.

\subsection{Capital Relacional}

A descrição da análise relacionada à dimensão Capital Relacional (CR) foi apresentada na Tabela 4 em um comparativo da percepção dos funcionários (nível individual) e dos gestores (nível coletivo).

Tabela 4 Indicadores do Capital Relacional

\begin{tabular}{|c|c|c|c|c|c|c|}
\hline $\mathbf{E}$ & Indicadores & Nível & No & Média & $\begin{array}{l}\text { Desvio } \\
\text { Padrão }\end{array}$ & $\begin{array}{l}\text { Valor } t \\
\text { GL } \\
\text { Sig. }\end{array}$ \\
\hline RV & $\begin{array}{l}\text { A empresa busca estabelecer um relacionamento de lealdade com seus } \\
\text { clientes (CR1) }\end{array}$ & $\begin{array}{l}\text { Func } \\
\text { Gestor }\end{array}$ & $\begin{array}{l}72 \\
11\end{array}$ & $\begin{array}{l}6,42 \\
6,91\end{array}$ & $\begin{array}{l}1,123 \\
0,302\end{array}$ & $\begin{array}{c}-1,440 \\
81 \\
0,154\end{array}$ \\
\hline RV & $\begin{array}{l}\text { Nas rotinas de trabalho a empresa considera principalmente a necessidade } \\
\text { do cliente (CR2) } \\
\text { Nas rotinas de trabalho a empresa considera principalmente a necessidade } \\
\text { do cliente e transmite essa ideia para seus funcionários (CR2) }\end{array}$ & $\begin{array}{l}\text { Func } \\
\text { Gestor }\end{array}$ & 69 & 6,61 & 0,826 & $\begin{array}{l}-1,18 \\
78 \\
0,239\end{array}$ \\
\hline RV & A empresa possui parcerias estabelecidas com os fornecedores (CR3) & $\begin{array}{l}\text { Func } \\
\text { Gestor }\end{array}$ & $\begin{array}{l}55 \\
11\end{array}$ & $\begin{array}{l}6,27 \\
6,00\end{array}$ & $\begin{array}{l}1,113 \\
1,183\end{array}$ & $\begin{array}{c}0,705 \\
13,774 \\
0,493\end{array}$ \\
\hline $\mathrm{RH}$ & $\begin{array}{l}\text { A empresa possui relações formais com parceiros e concorrentes para troca } \\
\text { de informações (CR4) }\end{array}$ & $\begin{array}{l}\text { Func } \\
\text { Gestor }\end{array}$ & $\begin{array}{l}49 \\
11\end{array}$ & $\begin{array}{l}4,65 \\
4,78\end{array}$ & $\begin{array}{l}1,953 \\
2,489\end{array}$ & $\begin{array}{r}-, 142 \\
9,891 \\
0,890\end{array}$ \\
\hline $\mathrm{RH}$ & A empresa tem uma boa reputação no mercado (CR5) & $\begin{array}{l}\text { Func } \\
\text { Gestor }\end{array}$ & $\begin{array}{l}73 \\
11\end{array}$ & $\begin{array}{l}6,70 \\
6,91\end{array}$ & $\begin{array}{l}0,617 \\
0,302\end{array}$ & $\begin{array}{c}-1,108 \\
82 \\
0,271\end{array}$ \\
\hline
\end{tabular}

Legenda: $\mathrm{E}=$ Elemento, $\mathrm{RV}=$ Relações Verticais, $\mathrm{RH}=$ Relações Horizontais.

Fonte: Elaboração própria.

Em relação às afirmativas nenhuma mostra variação significativa $(p<0,05)$ entre a percepção de gestores e funcionários. Dentre todas as dimensões do CI analisadas, esta apresentou os maiores índices de "prefiro não responder", por parte dos funcionários respondentes, em sua maioria do setor operacional. As afirmativas CR3 e CR4 obtiveram os menores números de respondentes válidos (55 e 49, respectivamente) se comparadas ao total da amostra (86). Logo, conclui-se que os funcionários que participaram da pesquisa, principalmente do setor operacional, têm pouco conhecimento sobre as relações da empresa com parceiros e concorrentes, pois optaram em não se pronunciar sobre o tema.
As afirmativas sobre as relações verticais que a empresa possui apresentaram índices superiores, variando de 6 a 6,91 pontos. Ou seja, tanto os funcionários quanto os gestores percebem de que a empresa desenvolve relacionamento de lealdade com seus clientes (CR1) e tem boa parceria com seus fornecedores (CR3). Sobre o fato de a empresa trabalhar através das necessidades dos clientes e transmitir essa ideia aos funcionários (CR2), os gestores (média $6,91)$ de modo geral acreditam que isso aconteça e os funcionários (média 6,41) têm essa mesma percepção. Diante disso, Delgado-Verde et al (2016) enfatiza o fato de que essas relações geram maior confiabilidade para empresa, consequentemente encaminhando-se 
para desenvolver a capacidade de compreender e assimilar o novo, melhorando seus resultados através de uma perspectiva inovadora. Com isso, a fidelização de clientes e fornecedores fornece subsídios para o crescimento da empresa no mercado, não somente pelos benefícios mais aparentes, mas também porque proporcionam o aumento do $\mathrm{CI}$, tornando a empresa mais competitiva em longo prazo.

Em relação às respostas obtidas nas entrevistas sobre essa temática, todos os gestores concordaram que a empresa possui uma relação sólida com seus clientes, salientando pontos como, produto de qualidade, equipe técnica eficiente, entrega rápida, atendimento de qualidade e flexibilidade na negociação. Ainda sobre essas relações verticais, Pacheco (2005) comenta elas agregam valor por meio da fidelidade, qualidade, velocidade e mercados melhorados. Entretanto, os gestores entendem que as relações com os fornecedores poderiam ser mais desenvolvidas, se comparado aos clientes.

No que diz respeito às relações horizontais, a afirmativa que apresentou menor média, tanto na percepção dos funcionários $(4,65)$ quanto na percepção dos gestores $(4,78)$, são as relações de parcerias e concorrentes para troca de informações (CR4). Como a percepção dos gestores está alinhada a dos funcionários, entende-se que a empresa não apresenta de maneira clara suas relações com parcerias e concorrentes. Além disso, as relações horizontais devem ser melhor desenvolvidas no ambiente interno já que grande parte dos funcionários não apresenta o conhecimento das interações que a empresa realiza com parceiros e concorrentes. Logo, sugere-se buscar possíveis alianças com parceiros e concorrentes, fortalecendo o Capital Relacional, pois isso pode gerar resultados positivos ao negócio.

No que se refere à reputação no mercado (CR5), os funcionários (média 6,70) e os gestores (média 6,91) identificam que a empresa possui uma considerável imagem externa, o que pode impactar diretamente na capacidade inovadora de produtos e no desempenho (COSTA, FERNÁNDEZ-JARDÓN, FIGUEROA DORREGO, 2014). Provavelmente, os resultados positivos da Indusquimy e sua posição no mercado, devem-se em grande parte a consideração dessa imagem.
A respeito dos documentos analisados sobre esse capital, nota-se que a empresa ocupa uma considerável fatia do mercado na sua área de atuação, pois apresenta relações fortalecidas em diversas regiões do país, como: Minas Gerais, Santa Catarina, Paraná, São Paulo, entre outras. Além disso, atua no exterior em países como: China, México, Paraguai, Peru dentre outros. O prêmio setorial recebido como destaque em exportação corrobora essa questão. Ademais, a empresa participa de feiras e eventos nacionais e internacionais e possui parcerias com associações da região, visando à aquisição e transferência de conhecimentos no setor.

As observações sobre o setor comercial e demais processos da empresa, possibilitaram verificar que a empresa possui suas relações verticais fortalecidas, principalmente com seus clientes, com os quais a interação é frequente e intensa. As práticas realizadas pela Indusquimy para fortalecer esse relacionamento com os clientes se concretizam na forma de visitas técnicas semanais, desenvolvimento contínuo de novos produtos e atividades extras de lazer. Além disso, quinzenalmente o diretor organiza uma reunião com a equipe técnica para analisar os pontos fortes e fracos do mercado.

\subsection{Discussão dos resultados}

A partir da análise das dimensões do CI da empresa Indusquimy, foi possível identificar a relação existente entre o conhecimento individual e o coletivo. Constatou-se que a empresa possui funcionários-chave que, por meio de seus conhecimentos, agregam valor ao negócio de maneira expressiva. Figueiredo (2005) sugere que esses conhecimentos sejam multiplicados por toda a empresa para tornar suas práticas mais eficientes, enfatizando a ideia de que o conhecimento individual possui um papel fundamental no desenvolvimento do conhecimento coletivo.

Para Fleury e Oliveira Jr (2014), o conhecimento coletivo acontece através das interações entre indivíduos vinculados ao mesmo grupo interno. Como é possível depreender com base nos resultados apresentados, há influência do conhecimento coletivo no desempenho individual e vice-versa e que, grande parte das vezes, funcionários e gestores têm a mesma percepção sobre o Capital Intelectual 
individual e coletivo. Apesar disso, esta interação entre os conhecimentos ainda precisa de aprimoramento, pois foi verificado que o compartilhamento do conhecimento se limita muitas vezes ao pequeno grupo aos quais se relacionam diretamente, mas que os funcionários ainda não têm uma visão do todo, não estando a par de vários aspectos estratégicos do negócio, especialmente no setor operacional. As construções do conhecimento organizacional são interativas e evoluem dinamicamente, promovendo mudanças de conduta, de atitude e adaptação de novos valores, tanto por parte do indivíduo, como do coletivo (REIS; NODARI; DORION, 2012). Logo, melhorando a relação entre os grupos são fortalecidos os relacionamentos da empresa como um todo, gerando um ambiente propício para o compartilhamento de conhecimentos, fortalecendo o capital coletivo, tornando a empresa mais inovadora e possibilitando melhor desempenho no mercado.

Assim, foi possível destacar, com os resultados, a existência de relação sobre o CII e CIC na empresa Indusquimy. $\mathrm{O}$ capital humano apresentou um acúmulo de conhecimento considerável, já que os conhecimentos sobre produtos e processos da empresa parecem bem internalizados conforme destacado por meio das diferentes formas da coleta de dados. Além disso, os funcionários possuem habilidades adequadas para os seus cargos fortalecendo a ampliação do CI. O que pode ter contribuído para isso é a permanência dos funcionários por longo período na empresa, fazendo com que o conhecimento permaneça internamente. Empresas com baixos índices de rotatividade em seu quadro funcional são caracterizadas por possuir uma cultura forte e bem disseminada. Ou seja, em ambientes em que os membros compactuam com os valores do negócio e por isso permanecem lá, pode servir como base para um capital humano estável. Fato que, corrobora com a percepção de Centenaro, Bonenberger e Maimar (2016), de que os fatores da cultura são fundamentais para gerenciar o conhecimento.

Entretanto, como os valores da empresa não são formalizados conforme destacou a pesquisa a definição formal das estratégias poderia contribuir para melhorar o desempenho do capital humano. Principalmente sobre as relações no ambiente interno com colegas de trabalho e gestores que são fundamentais para aquisição e manutenção do CI já que a troca de conhecimento e o trabalho em equipe fortalecem as organizações do conhecimento. Ademais, o que pode justificar a necessidade de desenvolvimento nesses aspectos é a condição de que o CII, aparentemente, é fortalecido e eficaz, fazendo com que não se estimule com tanta intensidade as trocas coletivas. Entretanto, de acordo com Costa, Fernández-Jardón e Figueroa Dorrego (2014) mesmo que a organização tenha pessoas e capacidades torna-se necessário integrar, partilhar e enriquecer a informação para criar e assimilar conhecimentos úteis e aplicáveis ao negócio.

Já o capital estrutural é considerado a infraestrutura que apoia o Capital Humano (EDVINSSON; MALONE, 1998). Essa infraestrutura na pesquisa é utilizada para a transferência e acúmulo de conhecimento, principalmente, pelos gestores. A inserção de um sistema de gestão eficaz favorece o desenvolvimento da empresa, pois permite a acessibilidade de informações de forma mais assertiva efacilitada, bem como, a gestão e utilização adequada deste conhecimento.

Por fim, os relacionamentos que uma empresa possui, definem seu posicionamento perante o mercado. Assim, torna-se importante que não apenas a gestão da empresa possua esse discernimento mas os funcionários de igual forma. Os relacionamentos com parceiros diretos como clientes e fornecedores é percebido de forma mais intensa objetivando o desenvolvimento de produtos com maior qualidade e a fidelização dos clientes, podendo refletir na aquisição de mercados melhorados, conforme Pacheco (2005). Já com concorrentes a relação é um pouco menos percebida desvelando a condição de dificuldade no compartilhamento de informações com concorrentes diretos.

\section{CONSIDERAÇÕES FINAIS}

Esse trabalho teve como objetivo analisar a relação entre o CII e CIC em uma indústria química da região do Vale dos Sinos. O argumento desta pesquisa teve como base o desenvolvimento das três dimensões do CI (Humano, Estrutural e Relacional) na percepção individual dos funcionários e na percepção dos gestores sobre o conhecimento coletivo da organização. Sobre o Capital Intelectual apresentou-se a seguinte composição: o Capital Humano 
relacionado aos conhecimentos, habilidades e atitudes dos indivíduos; o Capital Estrutural relacionado ao capital organizacional e a estrutura interna; e o Capital Relacional através das relações horizontais e verticais da organização com o meio externo.

Os resultados indicaram que a empresa possui um Capital Intelectual relativamente bem desenvolvido e que a percepção dos funcionários está alinhada à visão geral dos gestores. Esse aspecto é positivo e indica que a empresa deve seguir desenvolvendo esse ativo, fortalecendo ainda mais a sua competitividade e imagem. Sobre a dimensão Capital Humano os principais resultados foram: um conhecimento considerável dos funcionários sobre os produtos e processos da empresa e a disposição de funcionários com habilidades importantes para o cargo que executam, tendo influência direta e indireta nos resultados da empresa. Ao mesmo tempo, verifica-se que são necessárias melhorias quanto ao trabalho em equipe, contribuição com novas ideias e compartilhamento de conhecimento com os colegas, favorecendo a ampliação do CII e CIC.

Em relação à dimensão Capital Estrutural constatou-se que os funcionários possuem comprometimento com os objetivos e metas estabelecidas. Entretanto, esses índices são inferiores a outros indicadores, possivelmente pelo fato de que a empresa não possuir missão e valores estabelecidos. Além disso, as tecnologias são pouco utilizadas na rotina de trabalho dos funcionários, principalmente do setor operacional. Logo, torna-se relevante que a cultura organizacional seja formalizada, que as estratégias estejam mais claras e que os funcionários estejam mais informados. Também é fundamental a verificação de necessidade de novas tecnologias no setor operacional.

Sobre o Capital Relacional, as relações verticais estão fortalecidas, necessitando desenvolver de forma mais intensa as relações horizontais. Principalmente, as relações com concorrentes que ainda são pouco percebidas fato que poderia contribuir na aquisição de conhecimento sobre informações do setor de atuação como um todo. Adicionalmente, é importante que os funcionários tenham informações mais acuradas a respeito das parcerias, já que normalmente as parcerias são realizadas por níveis mais estratégicos.
Tornou-se perceptível a existência de um CII que se refere a todo o conhecimento e habilidade que cada funcionário possui. A soma do conhecimento que os funcionários da empresa possuem, apoiados na estrutura, cultura e relações horizontais e verticais condicionam o CIC. Quanto mais fortalecido o CII dos membros, maior o alcance de ganhos de CIC.

A pesquisa cumpriu com os objetivos propostos e indica a importância de se analisar o CI sobre diferentes ângulos, permitindo maior conhecimento sobre a relação estre os recursos individuais e coletivos das organizações e, desta forma, contribuindo com esta lacuna do conhecimento apontada na introdução. Como limitador se destaca a dificuldade da generalização dos resultados obtidos nesta pesquisa por se tratar de um estudo de caso, os resultados podem não ser os mesmos em outras realidades. Neste sentido, sugere-se como estudo futuro replicar a pesquisa em outras empresas possibilitando a comparação dos dados, a fim de identificar resultados mais conclusivos sobre a temática. Sugere-se, ainda, com a validação do instrumento de pesquisa, a ampliação da análise da relação proposta utilizando-se de métricas estatísticas mais sensíveis na identificação de especificidades que possam estar contidas nos dados coletados.

\section{REFERÊNCIAS}

AHUJA, Gautam. Collaborative networks, structural holes, and innovation: A longitudinal study. Administrative Science Quarterly, v. 45, p. 425-455, 2000.

ALVARENGA NETO, Rivadávia C.D. Gestão do conhecimento em organizações: Proposta de mapeamento conceitual integrativo. São Paulo: Saraiva, 2008.

ANTUNES, Maria T.P. Capital intelectual. 4 reeimp. São Paulo: Atlas, 2007.

ASSIS, Marcelino T. Indicadores de gestão de recursos humanos: usando indicadores demográficos, financeiros e de processos na gestão do Capital Humano. Rio de Janeiro: Qualitymark, 2005. 
ARNOSTI, José C.M., NEUMANN, Regina A., OLIVEIRA, Elizabeth C.M., YOMURA, Nobuya. Capital Intelectual: Reconhecimento \& Mensuração. 4 reeimp. Curitiba: Juruá, 2011.

BERTOLLA, Fernando L., ECKERT, Alex, DORION, Eric C. H., NODARI, Cristine H. Capital intelectual como recurso na retenção de clientes. Revista Pensamento Contemporâneo em Administração (UFF), v. 9, n.3, p. 155-168, 2015.

CABELLO-MEDINA, Carmen, LOPEZ-CABRALES; Alvaro, VALLE-CABRERA, Ramón. Leveraging the innovative performance of human capital through HRM and social capital in Spanish firms. International Journal of Human Resource Management, v. 22, n. 4, p. 807-828, 2011.

CABRITA, Maria R., BONTIS, Nick. Intellectual Capital and Business Performance in the Portuguese Banking Industry. International Journal of Technology Management, n.3, v. 43, p. 212-237, 2008.

CAMPBEL, David, RAHMAN, Mara R. A. A longitudinal examination of intellectual capital reporting in Marks \& Spencer annual reports, 1978-2008. The British Accounting Review, v. 42, p. 56-17, 2010.

CARVALHO, Fábio C.A. Gestão do Conhecimento. São Paulo: Person, 2012.

CENTENARO, Andressa; BONEMBERGER, Angela M.O., LAIMER, Claudionor G. Gestão do conhecimento e vantagem competitiva: estudo no setor metal mecânico. Revista de Ciências da Administração, v. 18, n. 44, p. 38, 2016.

COSER, Adriano. Modelo para análise da influência do Capital Intelectual sobre a performance dos projetos de software. 2012. Tese (Doutorado em Engenharia e Gestão do Conhecimento) Universidade Federal de Santa Catarina, Florianópolis, 2012. Disponível em: << http://btd.egc.ufsc.br/wp-content/uploads/2012/05/Adriano-Coser.pdf $>>$. Acesso em: 30 de set. 2016.
COSTA, Ricardo V.; FERNÁNDEZ-JARDON, Carlos; DORREGO FIGUEROA, Pedro. Critical elements for product innovation at Portuguese innovative SMEs: an intellectual capital perspective. 2014. 16 p, 322-338. Research Gate, Portugal. Disponível em: $<<$ https://www.researchgate.net/publication/265173450>>. Acesso em: 30 de set. 2016.

DAVENPORT, Thomas H.; PRUSAK, Laurence. Conhecimento empresarial: como as organizações gerenciam o seu Capital Intelectual. 14. ed. Rio de Janeiro, RJ: Campus, 2003.

DEAN, Alison, KRETSCHMER, Martin. Can Ideas be Capital? Factors of Production in the Postindustrial Economy: A Review and Critique. Academy of Management Review, v. 32, p. 573-594, 2007.

DELGADO-VERDE, Miriam, CASTRO, Gregório M., SALVADÓ, Javier A. Intellectual capital and radical innovation: Exploring the quadritic effects in tecnology-based manufacturing firms. 2016. 47 p. Elsevier, Madrid. Disponível em: <<www.elsevier.com/locate/ technovation $>>$. Acesso em: 30 de set. 2016.

DONATE, Mario J., PENA, Isidro, SANCHEZ, de Pablo. HRM practices for human and social capital development: Effects on innovation capabilities. The International Journal of Human Resource Management, v. 27, n. 9, p. 928-953, 2016.

DUMAY, John. A critical reflection on the future of intellectual capital: from reporting to disclosure. Journal of Intellectual Capital, v17, n 1, pp. 168 184, 2016.

EDVINSSON, Leif, MALONE, Michael S. Capital Intelectual. São Paulo: Makrons Books, 1998.

ENGELMAN, Raquel, FRACASSO, Edi, SCHMIDT, Serje, ZEN, Aurora. Intellectual capital, absorptive capacity and product innovation. Management Decision, v. 55, n. 3, p.474-490, 2017. 
ENGELMAN, Raquel; SCHMIDT, Serje; FRACASSO, Edi Madalena. Capital Intelectual: Adaptação e Validação de uma Escala para o Contexto Brasileiro. Revista Espacios, 2016.

FLEURY, Maria Tereza Leme (org); OLIVEIRA JR., Moacir de Miranda (org). Gestão estratégica do conhecimento: integrando aprendizagem, conhecimento e competências. 9 reimpr. São Paulo: Atlas, 2014.

FIGUEIREDO, Saulo P. Gestão do conhecimento: estratégias competitivas para a criação e mobilização do conhecimento na empresa: descubra como alavancar e multiplicar o capital intelectual e o conhecimento da organização. Rio de Janeiro: Qualitymark, 2005.

\section{GIL, Antônio C. Como elaborar projetos de pesqui-} sas. 4. ed. São Paulo: Atlas, 2002.

GIL, Antônio C. Métodos e técnicas de pesquisa social. 6. ed. São Paulo: Atlas, 2008.

HAIR, Joseph F., ANDERSON, Rolph. E., TATHAM, Ronald L. \& BLACK, William. C. Análise Multivariada de Dados. Porto Alegre: Bookman, 2005.

HOSS, Osni, ROJO, Claudio A., GRAPEGGIA, Mariana. Gestão de ativos intangíveis: da mensuração à competitividade por cenários. São Paulo: Atlas, 2010.

JARDON, Carlos M., MARTOS, Maria S. Intellectual capital and performance in wood industries of Argentina. Journal of Intellectual Capital, Vol. 10 n. 4, p. 600-16, 2009.

KIANTO, Aino, SAENZ, Josune, ARAMBURU, Nekane. Knowledge-based human resource management practices, intellectual capital and innovation. Journal of Business Research, v. 81, n. 2, p. 11-20, 2017.

KLEIN, David A. A gestão estratégica do Capital Intelectual: recursos para economia baseada em conhecimento. Rio de Janeiro: Qualitymark, 1998.
MALHOTRA, Naresh K. Pesquisa de marketing: uma orientação aplicada. Porto Alegre: Bookman, 2012.

MARQUES, Robson O., GOMES, Aline V. Analise de indicadores de Capital Intelectual: Estudo de caso na empresa atacadista. 2011. 22 p. Artigo (Pós-Graduação em Administração) - Pontifícia Universidade Católica de São Paulo, São Paulo, 2014. Disponível em: < http://revistas.pucsp.br/index.php/ rad/article/view/7797>. Acesso em: 09 de set. 2016.

NAHAPIET, Janine, GHOSHAL, Sumantra. Social capital, intelectual capital, and the organizational advantage. Academy of Management Review, v.23, p. 242-266, 1998.

PACHECO, Vicente. Mensuração e divulgação de Capital Intelectual nas demonstrações contábeis: teoria e empiria. 2005. Tese (Doutorado em Engenharia de Produção) - Universidade Federal de Santa Catarina, Florianópolis, 2005. Disponível em: <https://repositorio.ufsc.br/bitstream/handle $/ 123456789 / 102356 / 211336$.pdf? sequence $=1>$. Acesso em: 12 de set. 2016.

PROBST, Gilbert, RAUB, Steffen, ROMHARDT, Kai. Gestão do conhecimento: os elementos construtivos do sucesso. Porto Alegre, RS: Bookman, 2002.

PRODANOV, Cleber C., FREITAS, Ernani C. Metodologia do trabalho científico: métodos e técnicas da pesquisa e do trabalho acadêmico. Novo Hamburgo: Feevale, 2013.

REIS, Zaida, NODARI, Cristine H., DORION, Eric C.H. Individual, Collective Leadership and Spiral of Knowledge Creation in Organisations. In: IAMB, 2012, Warsaw. 12th IAMB Conference Proceedings. Warsaw: Silver Spring: International Academy of Management and Business, 2012.

ROOS, Johan, EDVINSSON, Leif, DRAGONETTI, Nicola C. Intellectual Capital: navigating the new business landscape. London: Macmillan Press, 1997. 
SCHMIDT, Paulo, SANTOS, José L. Avaliação de ativos intangíveis. 2. ed. São Paulo: Atlas, 2009.

STEWART, Thomas A. Capital Intelectual. Rio de Janeiro: Campus, 1998.

SUBRAMANIAM, Mohan, VENKATRAMAN, N. Determinants of transnational new product development capability: Testing the influence of transferring and deploying tacit overseas knowledge. Strategic Management Journal, v. 22, p. 359-378, 2001.

SUBRAMANIAM, Mohan, YOUNDT, Mark A. The influence of intellectual capital on the types of innovative capabilities. Academy of Management Journal, v. 48, n. 3, p. 450-463, 2005.

TAKEUCHI, Hirotaka; NONAKA, Ikujiro. Gestão do Conhecimento. Porto Alegre: Bookman, 2008.
UVEDA, Valdecir, DORION, Eric C. H., NODARI, Cristine H., MARCON, Silvia R. A. Reading: Conceptual Framework of Praxis in Organizations That Innovate. Gestão.Org, v. 12, n.2, p. 134-146, 2014.

VALE, José, BRANCO, Manuel Castelo, RIBEIRO, João. Individual intellectual capital versus collective intellectual capital in a meta-organization. Journal of Intellectual Capital, v. 17, n. 2, p. 279-297, 2016.

YIN, Robert K. Estudo de caso: planejamento e métodos. 5. ed. Porto Alegre, RS: Bookman, 2015.

ZANELLA, Liane C.H. Metodologia de estudo e pesquisa em administração. Florianópolis: Departamento de Ciências e Administração/ UFSC: CAPS: UAB, 2009. 